\title{
A Concept Model of Mining Monotowns Sustainable Development
}

\author{
Natalya Artukhova ${ }^{1}$, Irina Roshchina ${ }^{2, *}$, Galina Kalyanova ${ }^{2}$, and Mikhail $\mathrm{Katz}^{2,3,4}$ \\ ${ }^{1}$ T.F Gorbachev Kuzbass State Technical University, Economics Department, 650000 Veseniaya st. \\ 28, Kemerovo, Russia \\ ${ }^{2}$ Tomsk State University, Institute of Economics and management, 634050 Lenin Avenue, 36, Tomsk, \\ Russia \\ ${ }^{3}$ Tomsk State University of Control Systems and Radioelectronics, 634050 Lenin Avenue 40, Tomsk, \\ Russia \\ ${ }^{4}$ Tomsk Polytechnic University, 634050 Lenin Avenue 30, Tomsk, Russia
}

\begin{abstract}
This paper covers peculiarities and problems of monoindustrial mining towns in terms of sustainability and safety exemplified by one of territories in Russia. The work takes into account results of various studies in sustainability of natural resource driven economies from different countries. The sustainability issues of resource-driven monoindustrial territories are typical for all developing economies of such kind. Therefore, approaches already used in other countries can be appliedin solving such problems. The paper analyses differences in sustainability issues of monoindustrial and polyindustrial economies, especially those caused by the substantial impact of a town-forming enterprise (TFE). The research uses the anthropocentric faceted approach (AFA) to assess the economic impact of the TFEs. As exemplified by Leninsk-Kuznetsky, a monoindustrial town located in Kemerovo region, Russia, the paper describes the specificities of social and labor relations and the impact of the TFE on sustainable development and the sustainable safety of labor. The research also justifies the approach for monitoring the social economic growth of the monoindustrial economies considering the link between sustainability, business activity and the social responsibility of the TFE (Corporate Social Responsibility, CSR).
\end{abstract}

\section{Introduction}

"With the formal adoption of the UN Sustainable Development Goals (SDGs) and their launch in 2016, governments are globally tasked with developing pathways to achieve nationally prioritized targets that incorporate social, economic and environmental dimensions of sustainability, moving beyond sectoral approaches of the past» [1]. Sustainable Development Goalsinclude a wide range of topics (from poverty and malnutrition eradication to sustainable cities, economies and ecosystems).

\footnotetext{
*Corresponding author: riv58@yandex.ru
} 


\section{Materials and Methods}

Numerous authors contributed to the vast literature on the link between economic growth and natural resources. However, there can be no definite answers to these questions because the changes in economic development call for reinvestigation of the problem. So, for example, if before the XXth century natural resources played the pivot role in the economy, in the XXth century they were surpassed by capital and labor. Zaman et al. (2016) found that environmental conservation and human activities should be paid closer attention to in the coordinated development [2].

According to Nankani [3], Sachs and Warner [4,5] in such conditions the abundance of natural resources has a negative impact on economic growth in low and middle income economies [3-5].

Sachs and Warner [4, 5, 6, 7] introduced the concept of the «Resource Curse». Its means were that the countries with great natural resource wealth experienced slower growth than resource-poor countries [6-9]. According to John Dobra, Matt Dobra, Abdoulaye Ouedraogo "two common themes in the discussion of the minerals producing industry are "boom and bust"and the "resource curse" (or "Dutch Disease")".

J.Dobra, M.Dobra and A.Ouedraogo find that speaking of renewable resources, the concept of sustained yield is well known and relatively simple in principle. Yet, when it comes to non-renewable resources like minerals, the concept of sustainability becomes much more difficult to formulate. In fact, to most people the concept of the sustainable use of non-renewable resources appears downright paradoxical at first glance.

Thanh Le and Cuong Le Van conclude that despite a possible triggering of a negative growth rate, non-renewable resources are able to induce a higher growth rate under some conditions involving the intrinsic growth of renewable resources and the productivity of research activities [10].

Sachs and Warner $(1995,2001)$ have argued that a large natural resource export sector retards development in other sectors such as manufacturing. A large natural resource sector also distorts labor markets by increasing demand for relatively unskilled labor in some cases, reducing incentives for individual educational attainment (Hajkowicz, 2009) $[4,6,11]$.

It should be considered that the recent literatures on sustainability tend focus on other factors. The reason is that contemporary global environment abounds in examples of both successfully growing resource-poor (Hong Kong, Singapore, Switzerland) and wealthy (USA, Canada, Australia and Chile) economies. All this questions the validity of the«resource curse» (or «Dutch Disease») problem. Results of the recent studies prioritize institutional and demographic factors. It is supported in Arrow [12] who suggests thatmineral development may not be sustainable locally, if the depletion of the resource is not matched by local investments in physical and human capital» [12].

All the aforementioned calls further studies of monindustrial mining territories sustainability to consider the factor of labour (or rather a person), institutional factor and non-renewable resources.

The goal of this paper is to ground an approach to monitoring the socio-economic growth of monoindustrial territories featuring the model of a 'new economic man' which helps best capture the connection between sustainability, wellbeing and social responsibility of the town forming enterprise (TFE).

\section{Results and Discussion}


Economic science over its more than 2 century history has seen a lot of research on volatility of characteristics of economic man. As the economy and society develop, the main traits of economic man change too as reflected in the models of 'homo oekonomikus'.

If the theoretical models of economic man focus mainly on behavioral characteristics and man's reactions to economic 'signals', then we suggest an alternative approach where the focus is placed on the man's functions in the main aspects of life which can identify his essential characteristics. The need and necessity to consider a one-dimensional or personal man is predefined by the complexity and multifaceted nature of the man himself and his living environment.

There are various concepts of the aspects of life. For instance, Max Weber doesn't point out how many aspects there are, however G. Oakes identifies 6 spheres: religion, economy, politics, esthetics, as well as erotic, and intellectual aspects. But according to Weber the history of economy is a process of gradual economic structuring in line with its internal patterns.

This research considers the following aspects of human life: environment, society, state, economy and culture.

'One-dimensional' man is the product of a researcher's excessive focus on one of the aspects of human life. Such focuses correspond to respective models of 'one-dimensional' (personal) man:

1. Economy - homo oeconomicus (economic man).

2. State - institutional (contract) man.

3. Culture - cultural man.

4. Society - homo sociologicus [13-14].

5. Environment - environmental man.

6. Man - psychological man (homo psychologicus), - a model of a man as a wholesome informational system suggested by American psychologists J. Royce and A. Powell.

From the perspective of AFA one-dimensionality of existing models can be shown as follows:

- Classical, Neoclassical, and Keynesian schools primarily see the man as a worker;

- Marginalists see the man as a consumer;

- GermanHistorical school, Marxism and Evolutionism view the man as a socialized individual.

It should be considered that there are schools which take into account (to different extent) a two faceted nature of man (e.g. Institutionalism and Neo-institutionalism recognize the facets of a consumer and a socialized individual).

The necessity to abandon the one-dimensionality can be exemplified by entrepreneurs running a small business. They possess traits typical for two models - Economic Man(focus on maximization of profit, acquisition of resources, wealth etc.) and Institutional Man (focus on social status etc.).

The New Economy has to be driven not by a market man in its traditional sense (egoistic and rational), but a man possessing other important qualities, such as social responsibility, integrity, literacy oriented at social and not personal utility, etc.

The concept of the 'New Economic Man' has just started to develop, hence the wide variety of approaches to define its subject. However these approaches to a large extent imply constructing one-dimensional models of Economic Man emphasizing individual traits which demonstrate the attributes of the new economy, for example, 'a creative man'.

To isolate and formulate the emerging line of thought on the 'new economic man' model and avoid digressions to various traits of human character and their behavioral manifestation, we can use AFA. 
In our concept of the 'new economic man' typical for the 'new economy' we will use the methodological framework of neo-institutionalism adjusting it to the results of our research, as follows:

- modification the principle of 'methodological individualism' considering the social interaction concept (the object of analysis is the individual realizing his abilities in different aspects of life and making a choice to achieve his goals under the conditions of scarce resources. Collective action analysis implies viewing phenomena and processes from the perspective of interaction with not one individual but rather with communities of people formed by different criteria (social status, wealth, religious or political affiliation, etc.) and recognizing individuals (' a generalized other') rather than groups and organizations as participants of the social process. Altogether different communities should be formed by purposeful behavior of an individual and his ability to 'take another's role' and see how he is viewed by the others to interpret the situation and adjust his behavior;

- the concept of Economic Man (the models of the 'new economic man');

- activity as exchange (interaction of economic subjects cannot be viewed only through exchange; the man in the market economy identifies his preferences with goods; any other aspect of life is seen as a market for goods; the lines between the aspects of life are blurred);

- rationality (natural socio-humanitarian rationality and natural consensus rationality).

Among the non-renewable resources this research focuses mainly on coal as it is pivotal for the growth of many territories. Thus, e.g. in Lee we find that "Coal has been regarded as the most reliable and abundant resource in China's strategy, which occupies an important position in the energy industry and national economy. However, China's coal industry has changed since 2011 and coal-based regions are under pressure now. Coal-based regions face various problems, such as excessive rapid consumption of resources, serious ecological destruction, low-level environmental governance, unreasonable industrial structure, insufficient coordinated development power and so on" [15].

Our interest in China's experience in coordinating the economic growth, environment and resources in coal-based regions is well grounded, as Shanxi province is a typical coalbased province in China [15]. Similarly Leninsk-Kuznetsky is one of the main centers of coal mining in Kuzbass (Kuznetsky Coal Basin). However monitoring data shows that Leninsk-Kuznetsky ranks last in socio-economic growth among coal-mining SITs.

Mining represents an important economic sector for many countries, e.g., Canada, Australia, South Africa, Chile, and Peru.

Arango-Aramburo points out that "the problems within the mining sector are characterized by complex interactions among a large number of stakeholders: mining companies, who are often multinational; lawmakers, who make the broad rules; regulators, implementing the rules; the local population, that needs the economic opportunities associated with the projects; illegal miners: a heterogeneous group that "privatizes" the economic benefits of mining, ignoring the environmental damage that may arise from such exploitation; and a global market, where the prices are determined based on supply and demand. All of these stakeholders are embedded in a complex web of interdependence that is characterized by high uncertainty in the medium to long term because construction delays are long, rules can change rapidly, demand and prices can shift quickly, and environmental and social consequences are to a large extent unpredictable" [16].

These days social wellbeing of population in such areas to a large degree depends on the social and labor relations at TFEs and in the SITs in general, which calls for their further research.

The list of monoindustrial municipalities (or SITs) in Russia includes 319 towns with total employed population of, as of $01.01 .2017,5.9$ million people, 916,000 of which 
(15.4\%) are employed at the TFEs, while, as of July 2015, 16.6\% of employed people worked at the TFEs. 25\% are employed in SMEs (including entrepreneurs). It should be considered that the rate of employment in Russian SITs is significantly lower than that in the G7 countries - 68.6\% [17]. Statistics show that SMEs are not sufficiently developed in monoindustrial areas of Russia, whereas in the European Union, USA and JapanSMEs are responsible for more than $50 \%$ of employment [18].

For some 10 territories of Russia economic growth of SITs has special significance, because in these territories $20 \%$ of population are concentrated in monoindustrial economies (the country average is $9 \%$ ). Kemerovo territory has a record breaking value of $60.2 \%$ with population located across 24 SITs (most of which specialize in coal mining and have substantial populations). A third of these towns refer to the so-called 'red' zone, which means they are in a very difficult socio-economic position (these are coal-mining, iron industry and mining equipment manufacturing). Such data show a need for further studies in the area of SITs social wellbeing in connection with sustainable social and labor relations, especially in mining specialized areas.

Monitoring agency "News Effector" together with the Fund of regional research "Regions of Russia" conducted a study "Happiness Index of Russian Cities" the purpose of which was to create an integrated happiness index for Russia. 26,900 people from 100 most populated cities (11 of which were single industry towns) were interviewed. The resulting data showed that material wealth is an important factor of happiness but not the critical one. Other important factors were environment, social security and the feeling of improvement. Most single industry towns surveyed (9 out of 11) rank very low in the index (lower than 50), which means that residents of single industry towns are less happy than residents of poly-functional economies. Besides, most respondents are not satisfied with the state of environment, trends of municipal development, life safety and material well-being. Nearly half of all single industry towns surveyed are in aggravated social and economic crises. The rating is concluded by SITs of the Kemerovo territory (Novokuznetsk and Prokopievsk). Kemerovo territory itself can be called a monoindustrial territory (17 of the 34 municipalities are monoindustrial with narrow specialization in coal mining and iron industry, 64.7\%).

The area of social and labor relations at a TFE is, on the one hand, a condition for sustainable growth of the SIT, providing for social stability, growth of human resource potential, wellbeing and economic growth; on the other hand, social and labor relations are an object of sustainable development. Thus, regulating social and labor relations at a TFE is critically important for social wellbeing.

It should be considered that assessment of happiness and wellbeing of SITs is different from those of poly-functional economies. It is firstly conditioned by a high dependency of social wellbeing on the TFE, which determines not only the material wellbeing of the population, but also social, environmental wellbeing and happiness.

To conduct a more detailed analysis of the TFE's impact on the wellbeing and happiness of the population of the SIT we will use anthropocentric approach (AFA) to social and labor relations (Fig. 1) [19-20]. Social and labor relations at a TFE have a significant impact on those in the whole monoindustrial territory. 
Employee

(technical system)

Man
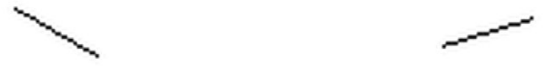

(multi-faceted being) in a

noninchustrial economy

Socialized Individual

(institutional system)

\section{Consumer \\ (social system)}

Fig. 1.A model of the man as a multi-faceted being in a monoindustrial economy.

The facet 'man-employee' plays the central role here, which means that through the influence on this role the facets 'man-socialized individual' and 'man-consumer' can be affected. But a full analysis calls for a more detailed study of all facets of Man in a monoindustrial economy.

It is important to identify the content of the facets taking into account the man's connection to the TFE, thus pointing out the two characteristics of this facet:

- "inside" the TFE;

- "outside" the TFE.

The impact of social and labor relations of the town forming enterprise SUEK-Kuzbass Inc. on the development of human potential and economic growth of Leninsk-Kuznetsky are shown in authors' publications [21].

It should be considered that during the crisis (2008-2009) the interdependency of the TFE and the SIT manifested more vividly. This period witnessed negative trends in the company's activity: decrease in the number of employees - by $8 \%$ in 2009 and by $18 \%$ in 2010 (to 2008); decrease of the gross payroll by $15 \%$ in 2010; cut down on investment and lower profit margin. The crises affected the territory even more resulting in higher unemployment, large surplus of labor force (6 unemployed to 1 vacant position) and decreased investment and GDP.

Peculiarities and problems of the social and labor relations at the town forming enterprise SUEK-Kuzbass Inc. and the monoindustrial town Leninsk-Kuznetsky are summarized by authors in the published research [19].

Safety is an essential element and the basis for sustainable growth. Safety and security should last long term as implied by the sustainability concept. To reflect the peculiarities of contemporary trends in social and labor relations in sustainability concept we suggest the term "sustainable safety" defined as a condition of sustainability and an indicator of sustainable development of the social and labor relationship and social wellbeing.

\section{Conclusion}

The specifics of the social and labor relations in the single industry town LeninskKuznetsky and at the local town forming enterprise bring us to the following conclusions:

First, society, economy and environment of the town highly depend on the TFE, especially in the part of social and labor relations, therefore negative trends in the 
specialization (town forming) industry may cause a decline in social wellbeing (especially in the times of recession) and increased social tension.

Second, the labor market is closed, labor force is highly homogenized and is primarily oriented at the needs and peculiarities of the specialization industry.

Third, the work conditions and safety of the employees are in the high risk zone (as conditioned by the mining industry) which can lead to declined health of the population.

Fourth, small businesses are insufficiently developed, which results in lower incomes of people employed at SMEs, low business activity, low share of small businesses in local GDP and consequently low diversification of social and labor sphere and the economy in total.

Finally, people's wellbeing and sustainable development of the SIT depend on the TFE's social policy, its social orientation and responsibility.

\section{References}

1. L. R. Sylvia, Ecosystem Services, 29, 70-82 (2018)

2. K. Zaman, A. Abdullah, A. Khan, Renew. Sustain. Energy, 44, 1263-1271 (2016)

3. G. Nankani, World Bank Staff Working Paper, 354, 678-683 (1979)

4. J. D. Sachs, A. M. Warner, J. Afr. Econ, 6:3, 335-376 (1997)

5. J. D. Sachs, A. M. Warner, Eur. Econ., 45, 827-838 (2001)

6. J. D. Sachs, A. M. Warner, Development Discussion Paper, 517 (1995)

7. J. D. Sachs, A. M. Warner, Am. Econ, 87, 184-188 (1997)

8. J. D. Sachs, A. M. Warner, J. Dev. Econ., 59, 43-76 (1999)

9. J. D. Sachs, A. M. Warner, Eur. Econ., 45:4-6, 827-838 (2001)

10. L. Thanh, L. V. Cuong, Journal Economic Modelling, 70, 215-229 (2018)

11. S. Hajkowicz, Land Use Policy, 26 (2), 471-478 (2009)

12. K. Arrow, J. Econ. Perspect, 18:3, 147-172 (2004)

13. S. Linderberg, Journal of Institutional and Theoretical Economics, 34:7, 211-232 (1990)

14. S. Lindenberg, Sociological Theory, 22:9, 99-113 (1985)

15. L. Li, Journal Resources Policy, 55, 80-86 (2018)

16. S. Arango-Aramburo, Socio-Economic Planning Sciences, 60, 99-113 (2017)

17. I. Roshina, N. Artyukhova, WELLSO 2016 Future Academy, 1, 43-50 (2017)

18. I. Roshina, N. Artyukhova, RRI 2016 Future Academy, 1, 823-829 (2017)

19. I. Roshina, N. Artyukhova, Economic and legal issues, 11, 194-198 (2015)

20. I. Roshina, N. Artyukhova, ITSMSSM 2016 Atlantis Press, 1, 435-438 (2016)

21. I. Roshina, N. Artyukhova, International Conference on Research Paradigms Transformation in Social Sciences, 28, 1-4 (2016) 